\title{
Ultrasound-targeted transfection of tissue-type plasminogen activator gene carried by albumin nanoparticles to dog myocardium to prevent
} thrombosis after heart mechanical valve replacement

\author{
This article was published in the following Dove Press journal: \\ International Journal of Nanomedicine \\ 19 June 2012 \\ Number of times this article has been viewed
}

\section{Jun Ji \\ Shang-Yi Ji \\ Jian-An Yang \\ $\mathrm{Xia} \mathrm{He}$ \\ Xiao-Han Yang \\ Wen-Ping Ling \\ Xiao-Ling Chen}

Department of Pathology and Cardiovascular Surgery, Shenzhen Sun Yat-Sen Cardiovascular Hospital, Shenzhen, Guangdong, People's Republic of China
Correspondence: Jian-An Yang Dongmenbei Road I02I, Shenzhen 5 I8020, People's Republic of China Tel +86 075525603198

Fax +86075 525507019 Email yangjianan@hotmail.com
Background: There are more than 300,000 prosthetic heart valve replacements each year worldwide. These patients are faced with a higher risk of thromboembolic events after heart valve surgery and long-term or even life-long anticoagulative and antiplatelet therapies are necessary. Some severe complications such as hemorrhaging or rebound thrombosis can occur when the therapy ceases. Tissue-type plasminogen activator (t-PA) is a thrombolytic agent. One of the best strategies is gene therapy, which offers a local high expression of t-PA over a prolonged time period to avoid both systemic hemorrhaging and local rebound thrombosis. There are some issues with t-PA that need to be addressed: currently, there is no up-to-date report on how the t-PA gene targets the heart in vivo and the gene vector for t-PA needs to be determined.

Aims: To fabricate an albumin nano-t-PA gene ultrasound-targeted agent and investigate its targeting effect on prevention of thrombosis after heart mechanic valve replacement under therapeutic ultrasound.

Methods: A dog model of mechanical tricuspid valve replacement was constructed. A highly expressive t-PA gene plasmid was constructed and packaged by nanoparticles prepared with bovine serum albumin. This nanopackaged t-PA gene plasmid was further cross-linked to ultrasonic microbubbles prepared with sucrose and bovine serum albumin to form the ultrasonictargeted agent for t-PA gene transfection. The agent was given intravenously followed by a therapeutic ultrasound treatment ( $1 \mathrm{MHz}, 1.5 \mathrm{w} / \mathrm{cm}^{2}, 10$ minutes) of the heart soon after valve replacement had been performed. The expression of t-PA in myocardium was detected with multiclonal antibodies to t-PA by the indirect immunohistochemical method. Venous blood t-PA and D-dimer contents were tested before and 1,2, 4, and 8 weeks after the operation.

Results: The high expression of t-PA could be seen in myocardium with increases in blood t-PA and D-dimer contents and thrombosis was prevented 8 weeks after operation.

Conclusion: We successfully fabricated an albumin nano-t-PA gene ultrasound-targeted agent that could prevent dog thrombosis after mechanical heart valve replacement. Our study provides an experimental basis for prevention of human thrombosis-related diseases.

Keywords: albumin nanoparticles, ultrasonic microbubbles, valve replacement

\section{Introduction}

Heart valve diseases are involved in prosthetic heart valve replacement. More than 300,000 prosthetic heart valve replacements are performed each year worldwide. ${ }^{1}$ There is a higher risk of thromboembolic events after heart valve surgery and longterm or even lifelong anticoagulative and antiplatelet therapies are necessary, ${ }^{2}$ which may induce complications such as hemorrhaging or rebound thrombosis when the 
therapy ceases. ${ }^{3}$ Several anticoagulant agents are commonly used clinically, including warfarin, heparin, and aspirin, ${ }^{4-6}$ especially in prevention of acute thrombotic events such as acute myocardial infarction, acute ischemic stroke and thrombosis after coronary bypass, transluminal balloon angioplasty, and stenting and prosthetic heart valve replacement. ${ }^{7-11}$ Tissue-type plasminogen activator (t-PA), another kind of thrombolytic agent, is a 527-aa residue serine protease and performs the primary role in fibrinolysis by preferentially catalyzing the conversion of the proenzyme plasminogen to plasmin in the presence of fibrin. ${ }^{12,13}$ t-PA functions relatively clot-specific because of its high affinity for fibrin-plasminogen complexes via a fibronectin-like finger domain of lysine binding sites near the amino terminus and because of its relatively poor activity in the absence of fibrin. ${ }^{14,15}$ Hepatic metabolism represents the primary clearance mechanism for t-PA, and the enzyme has a half-life of 5-10 minutes in circulation. Although thrombolytic therapy of systemically administered recombinant t-PA has become the standard clinical treatment for acute myocardial infarction and has also been proven effective in improving the neurologic outcome in patients with acute ischemic stroke, significant complications remain. The central problem is hemorrhaging, particularly pulmonary or intracerebral hemorrhages, ${ }^{16,17}$ each of which can be life threatening. Since the cDNA of t-PA was successfully cloned, a t-PA reversetranscript virus vector could be constructed and transfected in vitro to the epithelial cells with a high expression of t-PA protein. It was demonstrated experimentally that thrombosis and restenosis after coronary stenting or bypass could be prevented with a long-term outcome when the transfected epithelial cells were spread on the surface of the stent or covered on vascular anastomosis. ${ }^{18,19}$ Gene therapy offers a method of local high expression of t-PA over a prolonged time period to avoid both systemic hemorrhaging and local rebound thrombosis. There are some issues with t-PA that need to be addressed: currently, there is no up-to-date report on how the t-PA gene targets the heart in vivo and the gene vector for t-PA needs to be determined. In an earlier study, we constructed a t-PA gene plasmid and transfected it to pig myocardium, using surgery dacron suture as gene vector, and successfully prevented thrombosis after valve replacement and anastomostic restenosis after coronary bypass..$^{20,21}$ Although the surgery dacron suture caring gene had been proved to be safe, convenient, and effective, it was alien and traumatic and unfavorable for patients as drug carrier.

Using polymer-constructed nanoparticles as a carrier for gene transfection is a new method developed in the past few years. ${ }^{22}$ Albumin has been used as a nanoparticle carrier because of its high biocompatibility, biodegradability, no immunogenicity, and no cellular toxicity. ${ }^{23}$ Albumin is positively charged in a tart medium. The nanoparticles made by albumin can absorb gene DNA with negative charges by static electricity. Directly injecting an objective gene loaded with plasmid DNA or an adenovirus vector to the targeted tissues for gene expression is the major method in modern experimental study. This method has had difficulty receiving clinical approval because of traumatic conclusions and immunogenicity. In vivo distribution of a drug or a gene carried by nanoparticles can be changed by modification of the nanoparticle surface, which displays the targeting of nanoparticles. The nanotargeting consists of two patterns: active and passive. The former has real significance and includes physical-chemical (such as PH-sensitive, temperature-sensitive, and magnetic targeting) and biological targeting (such as antigen-antibody, receptor-ligand targeting), which have been commonly used in nanotargeting studies. The drug or gene can be precisely sent to the targeted organ or diseased region for treatment or transfection. ${ }^{24}$ Ultrasound contrast agents have been used in diagnostic ultrasound imaging in the past few years ${ }^{25}$ and can also carry drugs or genes to select targeted tissues and cells for treatment or transfection. ${ }^{26}$ These methods have been experimentally confirmed to be effective, safe, and nontraumatogenic. ${ }^{27}$ The fundamental principles of ultrasound for targeted treatment are: (1) cavitation and machinery effects produced by the therapeutic ultrasound make the cell membrane reversible injury and increase in permeability, (2) the capillary vessels $(\leq 7 \mathrm{~mm})$ in the ultrasound field are injured and interspaces between endothelial cells become wide, through which the drug or specific gene can get to targeting tissue, ${ }^{28}$ and (3) when the ultrasound microbubbles in blood circulation pass through the tissue or organ treated with the ultrasound, they are quickly destroyed and the carried drug or gene is very easily released to tissue or organ. Systemic toxicity and side effect produced by the drug and gene significantly decrease because of targeted localization. ${ }^{29}$ We utilized the biological characters of albumin nanoparticles and the targeting of ultrasound microbubbles to realize t-PA gene targeting therapy, which was not reported worldwide.

In this study, a dog model of mechanical tricuspid valve replacement was made. A highly expressive t-PA gene plasmid was constructed and packaged by the nanoparticles prepared with bovine serum albumin. This nanopackaged t-PA gene plasmid was further cross-linked to ultrasound microbubbles prepared with sucrose and bovine serum 
albumin (BSA) to form the ultrasound-targeted agent for t-PA gene transfection. This agent was given intravenously followed by a therapeutic ultrasound treatment on the surface of the heart soon after tricuspid valve replacement. The expression of t-PA in the myocardium was detected and venous blood t-PA and D-dimer contents were tested before and 1,2, 4, and 8 weeks after operation. Effectiveness of the nanopackaged t-PA gene plasmid on thrombosis in heart cavities, general blood coagulation, and fibrinolysis was observed.

\section{Materials and methods}

\section{Animals}

Twenty-six healthy dogs, male, 30 to $35 \mathrm{~kg}$ in weight were used in the study and provided by Southern Medical University Animal Center, Guangzhou, Guangdong Province, China. All animal experiments were performed in compliance with the animal protection policy of the Chinese government (license SYXK Guangdong) and the standards of bioethics and biosecurity of our institute committee.

\section{Main reagents and instruments}

Chinese hamster ovary (CHO) cell line, pSecTag2B plasmid, Escherichia coli JM109, rabbit anti-human t-PA multiclonal antibody, fluorescein isothiocyanate coupled with sheep anti-rabbit immunoglobulin-G antibody, rabbit anti-sheep multiclonal antibody, immunohistochemical reagents, and bovine serum albumin were purchased from JingMei Biotech (Shenzhen, China). Restriction enzymes Hind3, Kpn1, BamH1, and Xho1, Vent DNA polymerase, T4 DNA ligase, polymerase chain reaction (PCR) product purification kit, and DNA marker DL2000 were purchased from New England Biolabs (Hong Kong, China). Mitral mechanic valves were the product of St Jude Medical (St Paul MN). Perfluoropropane (Halocarbon-218) was supplied by JieRui Co, Ltd (Fushan, China). Zeta potential analyzer was a product of Brookhaven Instruments (Holtsville, NY). Diagnostic ultrasonic generator (PHILIPS-iE33) was a product of PHILIPS (Tokyo, Japan). The therapeutic ultrasound Unit (US-700) was made by ITO Co, Ltd (Kanagawa, Japan).

\section{Construction and expression of the pSecTag2B-t-PA gene}

Three expressed sequence tag sequences were obtained from Internet BLAST according to the t-PA gene sequence. The ID numbers were 6251209, 4861268, and 5190656. The primers were synthesized as follows: t-PA-1F: 5'-CCC AAG CTT ATG GAT GCA ATG AAG AGA GGG- 3', t-PA-1R:
5'-GGG GTA CCA CGG TAG GCT GAC CCA TTC-3', t-PA-2F: 5'-GGG GTA CCC ACA GCC TCA CCG AGT CG-3', t-PA-2R: 5'-CGG GAT CCA GCA GGA GCT GAT GAG TAT GCC-3', t-PA-3F: 5'-CGG GAT CCT CTC TGC CGC CCA CTG CT-3', t-PA-3R: 5'-CCC TCG AGG CGG TCG CAT GTT GTC AC-3'. As the PCR amplification template, three expressed sequence tag clone strains were abstracted and the three t-PA fragments were amplified. The pSecTag 2B and three t-PA fragments t-PA-1, t-PA-2, and t-PA-3 were digested by Hind 3 and Xho1, Hind 3 and Kpn1, Kpn1 and BamH1, and BamH1 and Xho1, respectively. These enzymatic products were purified with the PCR product purification kit and were linked by T4 DNA ligase at $14^{\circ} \mathrm{C}$ overnight. The linked products were transfected to E. coli JM109 and the resistance colony in the aminobenzyl penicillin LB plate culture was chosen. This t-PA plasmid was sequenced and was transfected to $\mathrm{CHO}$ cells by calcium phosphate coprecipitation. The expression of t-PA was detected using a rabbit anti-human t-PA multiclonal antibody by the indirect immunofluorescence method.

\section{Preparation of BSA nanoparticles loaded with t-PA gene plasmid}

The preparation of BSA nanoparticles loaded with t-PA gene plasmid was according to the methods published by Arnedo et $\mathrm{a}^{22}$ and Zhang et a ${ }^{30}$ with some improvement. Briefly, $2 \mathrm{mg}$ t-PA plasmid DNA was incubated with $10 \mathrm{~mL}$ albumin aqueous solution ( $1 \% \mathrm{w} / \mathrm{v}$; $\mathrm{pH} 5.5)$ for 30 minutes. Then, this aqueous phase was desolvated with ethanol dropwise (ethanol:water $=2: 1$ ). The coacervates were hardened with $30 \mu \mathrm{L}$ glutaraldehyde (concentration: $0.5 \%, \mathrm{w} / \mathrm{v}$ ) for 2 hours. After the ethanol was eliminated by evaporation, the nanoparticles were purified by centrifugation at 17,000 rpm for 30 minutes to eliminate free albumin and excess crosslinking agent. The purified nanoparticles by centrifugation were resuspended in pure water and dispersed with ultrasound generator ( $180 \mathrm{~W}, 20 \mathrm{kHz}$, for 30 seconds) and stored at $4^{\circ} \mathrm{C}$ for further use. The amount of albumin transformed into nanoparticles was determined by a standard bicinchoninic acid protein assay. The pellet of nanoparticles obtained after centrifugation was digested with $\mathrm{NaOH} 0.1 \mathrm{M}$ for 2 hours at room temperature. The resulting solution was analyzed with a spectrophotometer at $562 \mathrm{~nm}$. The resulting absorbance was compared with the data obtained after the same digestion of a control albumin solution. The stability of nanoparticles was investigated in RPMI 1640 cell culture medium supplemented with FCS at $37^{\circ} \mathrm{C}$ over a time period of 48 hours by turbidity and particle size measurements. Some of the 
nanoparticles were taken for particle size, morphological observation, surface zeta potential, envelopment rate, and the electrophoresis.

\section{Preparation of ultrasound microbubbles}

The albumin ultrasound microbubbles were prepared according to the method reported by Du et $\mathrm{al}^{31}$ and $\mathrm{Li}$ et $\mathrm{al}^{32}$ with some improvement. $10 \mathrm{~mL}$ BSA solution $(5 \%, \mathrm{w} / \mathrm{v})$ with sucrose (final concentration: 10\%, w/v) was prepared in $50 \mathrm{~mL}$ plastic centrifuge tube and saturated with oxygen and perfluoropropane (flow rate: $6 \mathrm{~mL} / \mathrm{minute}$ ) by turns for 10 minutes and dispersed with an ultrasound generator ( $180 \mathrm{~W}, 20 \mathrm{kHz}$, for 1 minute). All procedures were operated under sterile conditions. The prepared microbubble solution was stored at $4^{\circ} \mathrm{C}$ for further use.

\section{Linkage of nanoparticles to microbubbles}

Nanoparticles loaded with t-PA gene plasmid (containing $1 \mathrm{mg}$ plasmid DNA) were mixed with $5 \mathrm{~mL}$ microbubbles (containing $1.0 \times 10^{9} / \mathrm{mL}$ ) at the room temperature. Ten microliters of $50 \%$ glutaraldehyde (final concentration: $0.1 \%, \mathrm{w} / \mathrm{v}$ ) was added to the prepared mixture for 2 hours at $4{ }^{\circ} \mathrm{C}$. The linked product was centrifuged at $200 \mathrm{rpm}$ for 1 minute and the floatage was taken and washed three times with $0.9 \%$ sodium chloride under centrifugation at $200 \mathrm{rpm}$ and the supernatant was stored at $4^{\circ} \mathrm{C}$ for ultrasound-targeted transfection.

\section{Dog tricuspid valve replacement and gene transfection}

Seventeen dogs were randomly divided into two groups: control $(n=8)$ and experimental $(n=9)$. The tricuspid valve replacements were carried out on the animals under general anesthesia $(25 \mathrm{mg} / \mathrm{kg}$ sodium pentobarbital for induction and $0.05 \mathrm{mg} / \mathrm{kg}$ fentanyl citrate for anesthesia maintenance, $0.6 \mathrm{mg} / \mathrm{kg}$ rocuronium bromide for muscle relaxation) and extracorporeal circulation method. In the experimental group, the heart was observed with two-dimensional-diagnostic ultrasound soon after intravenously injecting $20 \mathrm{~mL}$ (containing $4 \mathrm{mg}$ plasmid DNA) of linked ultrasound microbubbles and a strong resonance of the ultrasound signal was observed. After that, therapeutic ultrasound $\left(1 \mathrm{MHz}, 1.5 \mathrm{w} / \mathrm{cm}^{2}, 10\right.$ minutes, according to Ling et $\mathrm{al}^{33}$ with some improvements) was given on the surface of the anterior wall of the right ventricular; afterwards, normal heart resonance was observed. In the control group, a physiologic saline injection with the ultrasound treatment was given after the surgical operation. In addition, each of $20 \mathrm{~mL}$ microbubbles and nanoparticles with blank plasmid $(n=3)$, nanoparticles and t-PA plasmid without microbubbles $(\mathrm{n}=3)$, and microbubbles without t-PA plasmid nanoparticles $(n=3)$ was given for experimentrelated controls. All of the animals were observed for 8 weeks after the operation. Venous blood was taken before and after operation (1, 2, 4, and 8 weeks) to estimate t-PA and D-dimer contents and prothrombin time.

\section{Specimen preparation and examination}

When dogs died or the experimental period finished, dog hearts were examined pathologically. The thrombosis in heart cavities was observed. The myocardium treated with ultrasound was taken for histopathological analysis and immunohistochemical stain. t-PA expression was detected with multiclonal antibodies to t-PA by the indirect immunohistochemical method. Other organs including lungs, kidneys, and livers were taken for transfection specificity and general toxicity evaluation.

\section{Statistical analysis}

Statistical evaluation was done with Student's $t$-test. The results were expressed as $\mathrm{x} \pm \mathrm{s}$. Means were considered significantly different when $P<0.05$.

\section{Results}

\section{Amplification of pSecTag2B-t-PA and gene expression}

The linked products of pSecTag $2 \mathrm{~B}$ and three t-PA fragments (t-PA-1, t-PA-2, and t-PA-3) were transfected to E. coli JM109 and the aminobenzyl penicillin resistance colonies were selected and amplified. This t-PA plasmid DNA was purified and sequenced and transfected to $\mathrm{CHO}$ cells by calcium phosphate coprecipitation. The expression of t-PA was detected with a rabbit antihuman t-PA antibody by the indirect immunofluorescence method. The results are presented in Figure 1: a strong green fluorescence in transferred $\mathrm{CHO}$ cells was observed (Figure 1A1). There was a negative reaction in control cells without t-PA plasmid transfection (Figure 1A2).

\section{Characterization of the nano-t-PA gene plasmid}

Zeta potential analysis showed that the nanoparticle size ranged from 49.10 to $273.50 \mathrm{~nm}$ and was $132.80 \mathrm{~nm}$ on average with even distribution. The polydispersity index was 0.333 and surface Zeta potential ranged from +31.32 to $+41.42 \mathrm{mV}$ (Figure 1B). The encapsulation rate of the plasmid DNA was $73.58 \%$ according to the following formula: $\left(\mathrm{W}_{\mathrm{g}}-\mathrm{W}_{\mathrm{f}}\right) / \mathrm{W}_{\mathrm{g}} \times 100 \%$, where $\mathrm{W}_{\mathrm{g}}$ : the initial plasmid 


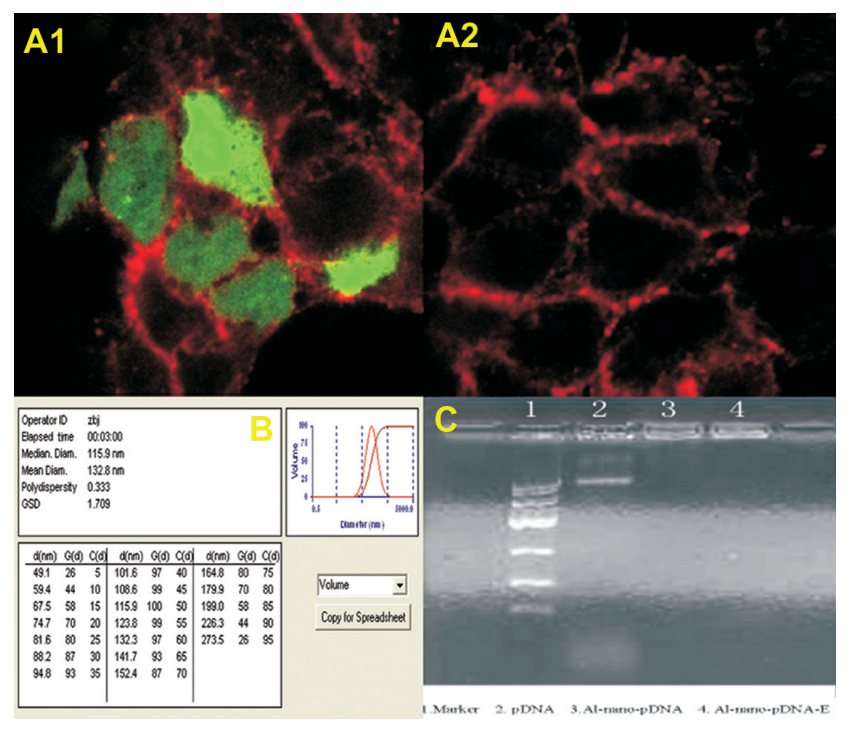

Figure I (AI) A strong green fluorescence in t-PA-transferred $\mathrm{CHO}$ cells was seen; (A2) A negative reaction in control cells without t-PA plasmid transfection; immunofluorescence 400×; (B) Characterization of nano-t-PA gene plasmid analyzed with Zeta potential analyzer; (C) The result of $0.9 \%$ agarose gel electrophoresis. Notes: I: Marker; 2: pDNA; 3: Albumin-nano-pDNA; 4: Albumin-nano-pDNA with DNase I digestion.

Abbreviations: t-PA, tissue-type plasminogen activator; $\mathrm{CHO}$, Chinese hamster ovary; p-DNA, plasma DNA.

DNA added and $\mathrm{W}_{\mathrm{f}}$ : the amount of plasmid DNA determined in the supernatants obtained during the purification steps. The amount of albumin transformed into nanoparticles was determined by bicinchoninic acid protein assay. A rectilinear calibration curve from 10 to $100 \mu \mathrm{g} / \mathrm{mg}$ was performed using a control albumin solution in $\mathrm{NaOH} 0.1 \mathrm{M}\left(\mathrm{r}^{2}>0.9573\right)$. Regarding nanoparticle stability, no differences in particle size or particle concentration in the medium (data not shown) were observed, indicating a high stability of the nanoparticles under cell culture conditions. These results met the need of the experimental study.

\section{Gel retardation and DNase I protection}

The plasmid DNA packaged by the nanoparticles with or without DNase 1 digestion could not move in the electric field and was retarded in the initial well (DNA: albumin was $1: 100$ ) in $0.9 \%$ agarose gel electrophoresis (Figure 1C). The plasmid DNA was digested by the DNase 1 and the moving strap in the gel electrophoresis could not be seen, indicating that the nanoparticles could protect the plasmid DNA from the DNase 1 digestion.

\section{Morphological and physical features of ultrasound microbubbles}

The size of the prepared microbubbles was $2 \mu \mathrm{m}$ to $5 \mu \mathrm{m}$ in diameter and cystic with very good dispersity, which could fit the vascular ultrasound visualization (Figure 2). Albumin microbubbles containing $10 \%$ sucrose were heat-resistant $\left(40^{\circ} \mathrm{C}, 30\right.$ minutes) and could be stored at $4^{\circ} \mathrm{C}$ for 30 days without morphological change.

\section{Ultrasound imaging and targeted transfection}

Figure 3 showed dog heart ultrasound imaging before and after ultrasound treatment. After intravenously injecting microbubbles with nano-t-PA gene plasmid, the heart ultrasound visualization increased obviously in comparison to preinjection and decreased to the baseline image following the ultrasound treatment. The same was found when microbubbles and nanoparticles with blank plasmid and microbubbles without t-PA plasmid nanoparticles were injected (results not shown). There were no changes in ultrasound imaging found in the control group and in experimentrelated control group of nanoparticles with t-PA gene plasmid (results not shown).

\section{Pathology and t-PA expression}

The replaced mechanical valves were well sutured and no perivalvular leakage was found in all operated animals. In the control group, only three animals were alive at the end of the observation period. Five animals died at days 19, 22, 29, 43 , and 55 after operation. The death rate was $62.5 \%$. The main cause of death was heart failure. In these cases, thrombi were found in right heart chambers and on valve surfaces and they usually extended from the juncture of the valve ring and leaflet to the right atrium or ventricle, and even filled the pulmonary arteries. There were more or less thrombi found in the live control hearts (Figure 4-1). In the experimental group, there was no thrombus found in the hearts (Figure 4-2) and all animals were alive at the end of the observation period.

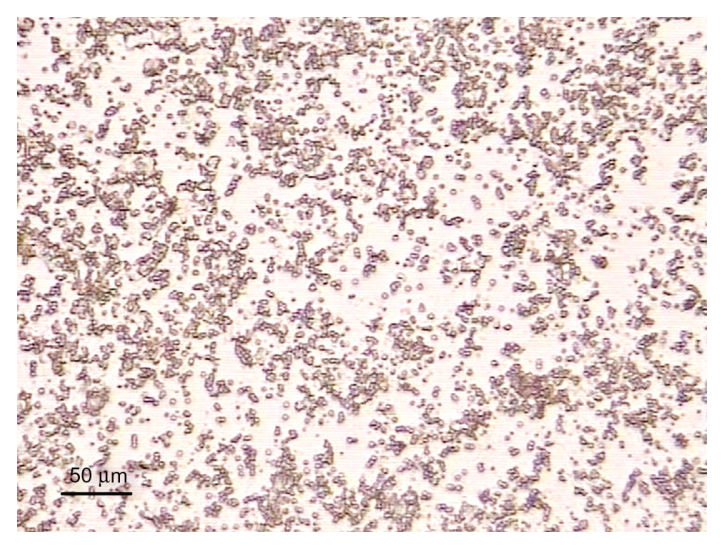

Figure 2 The size of prepared microbubbles were 2 to $5 \mu \mathrm{m}$ in diameter and cystic with very good dispersity under microscope $400 \times$. 


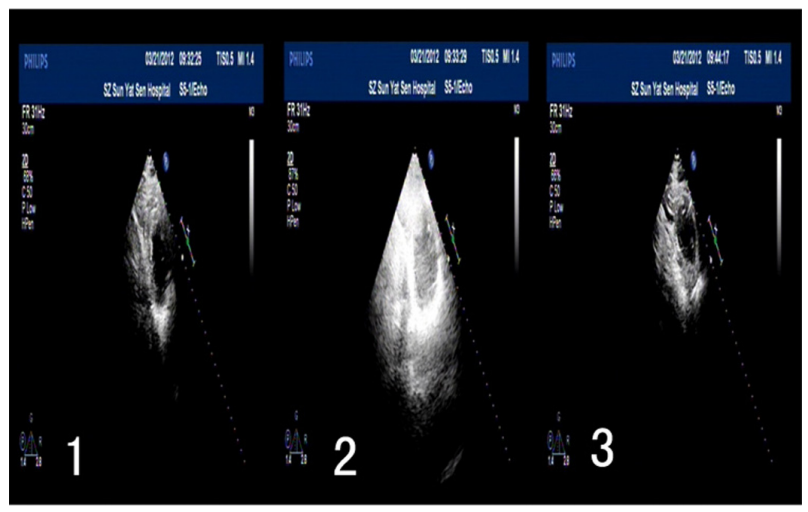

Figure 3 Change of heart ultrasound imaging before and after ultrasound treatment (parameters: FILIPS-iE33, 2D, FR3IHz, transducer: S5-I/Echo).

Notes: I: before ultrasonic treatment; 2: injection of the microbubbles with increased visualization of heart; 3: after ultrasonic treatment with decreased heart visualization to normal.

Histopathology showed that myocardial cells exposed to ultrasound field were larger than normal myocardial cells with rich cytoplasm. Immunohistochemical analysis was performed on all heart samples. t-PA-positive cells were only observed in all heart tissues in the experimental group, which included myocardial, local vascular, and interstitial cells exposed to ultrasound field (Figure 5A). No positive cells were found in heart tissues in control (Figure 5B), in experiment-related control groups and in other tissues including livers, kidneys, and lungs (Figure 5C-E).

\section{Venous blood t-PA and D-dimer}

Changes in blood t-PA and D-dimer contents before and 1, 2, 4, and 8 weeks after operation were showed in Table 1. t-PA and D-dimer contents in the experimental group greatly increased the first week after operation and were kept at high levels until 8 weeks in comparison with those of preoperation. In the control group, two values slightly increased after the operation, but no statistical difference was observed at 2,4 , and 8 weeks and only a statistical difference was seen 1 week postoperation. When comparing two values in every week postoperation with two groups, we could see significantly

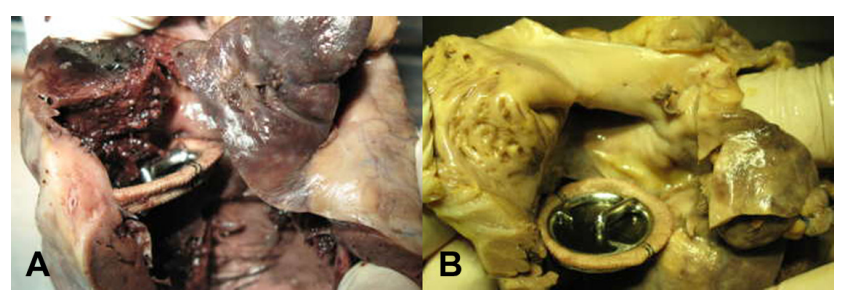

Figure 4 (A) Thrombi found in the right atrium and ventricle in control group; (B) There was no thrombus found in heart in experimental group. higher levels in the experimental group than the control group at 2,4 , and 8 weeks.

\section{Prothrombin time and international normalized ratio}

Changes in blood prothrombin time and international normalized ratio (INR) before and 1, 2, 4, and 8 weeks after operation were shown in Table 2 . There was no significant difference in prothrombin time and INR before and after operation, and also between the two groups in different weeks.

\section{Discussion}

In this work, a constructed albumin nano-t-PA gene plasmid cross-linked to albumin ultrasonic microbubbles was target transfected to dog myocardium under the guidance of therapeutic ultrasound and a highly expressive t-PA in myocardium followed by increase in blood t-PA and D-dimer was identified. Thrombosis after mechanical heart valve replacement was prevented. We demonstrated in several experimental studies that the constructed t-PA plasmid used in the present study carried by surgery dacron suture or chitosan nanospheres could also be transfected to dog myocardium and skeleton muscle with highly expressive t-PA. ${ }^{21,34}$ With some differences to the present study, all those methods were traumatic because of suturing or injecting to local tissues and might be only suitable for experiment or surgery.

We selected albumin for nanoparticle preparation because it was easy to link to the protein ultrasound agent for

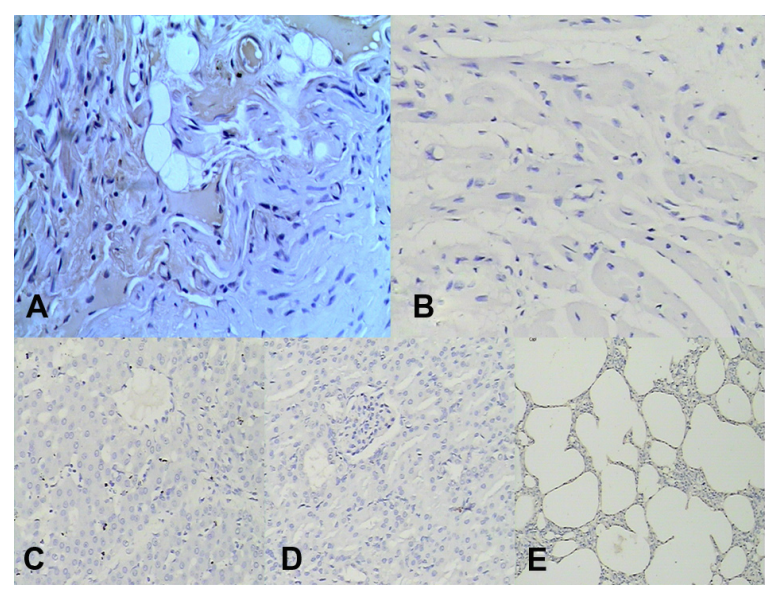

Figure 5 (A) t-PA-positive reaction was seen in myocardial, vascular, interstitial cells of the heart tissue exposed to ultrasonic field. There was no positive reaction observed in the same tissue without ultrasound in experimental group; (B) No t-PA positive cells were found in heart tissue in control group; (C) No t-PA positive cells were found in liver; (D) No t-PA positive cells were found in kidney; immunohistochemical stain 200x; (E) No t-PA positive cells were found in lung; immunohistochemical stain I00X.

Abbreviation: t-PA, tissue-type plasminogen activator. 
Table I t-PA and D-dimer contents before and after valve replacement $(\mu \mathrm{g} / \mathrm{mL}, \mathrm{x} \pm \mathrm{s})$

\begin{tabular}{|c|c|c|c|c|c|c|}
\hline \multirow[t]{2}{*}{ Time (week) } & \multicolumn{2}{|c|}{ Control group } & \multirow[t]{2}{*}{ Cases } & \multicolumn{2}{|c|}{ Experimental group } & \multirow[t]{2}{*}{ Cases } \\
\hline & t-PA & D-dimer & & t-PA & D-dimer & \\
\hline Before & $0.19 \pm 0.02$ & $83.68 \pm 5.99$ & 8 & $0.18 \pm 0.10$ & $87.26 \pm 6.57$ & 9 \\
\hline \multicolumn{7}{|l|}{ After } \\
\hline 1 & $0.4 \mathrm{I} \pm 0.04 *$ & $248.43 \pm 44.89 * *$ & 8 & $0.60 \pm 0.06 * *$ & $607.97 \pm 61.22 * *$ & 9 \\
\hline 2 & $0.31 \pm 0.05$ & $94.98 \pm 15.67$ & 8 & $0.7 I \pm 0.07^{* *}$ & $748.12 \pm 55.12^{*}$ & 9 \\
\hline 4 & $0.30 \pm 0.03$ & $74.37 \pm 9.96$ & 6 & $0.76 \pm 0.07 * *$ & $771.97 \pm 78.32 * *$ & 9 \\
\hline 8 & $0.28 \pm 0.02$ & $79.68 \pm 10.47$ & 3 & $0.75 \pm 0.05^{* *}$ & $764.21 \pm 54.23 * *$ & 9 \\
\hline
\end{tabular}

Notes: $* P<0.05$ vs before operation; $* * P<0.01$ vs before operation.

Abbreviation: t-PA, tissue-type plasminogen activator.

targeting purposes..$^{33}$ There are two methods for nanoparticles to carry a gene. One is the single-step method, in which the gene is added to albumin solution before nanoparticles are prepared and the gene DNA is encapsulated in a matrix of nanoparticles. This method has some advantages because of higher gene content, delayed and controllable release, enzyme resistance, and a longer transfective outcome. The other method is the two-step method, in which, albumin nanoparticles are prepared before the gene is added. Gene DNA is more easily bound to surface of nanoparticles with greater positive charge when adjusting the solution to be tart. The nanoparticles made by this way are equal in size and controllable in diameter, but without those advantages mentioned above. ${ }^{35,36}$ In this study, the one-step method was used to prepare nano-t-PA gene plasmid, which met the needs of the study because of suitable size (132.0 nm in diameter), good dispersity, high encapsulation rate $(73.58 \%)$, and effective DNase 1 protection.

Albumin can be cross-linked to another protein by glutaraldehyde. Thus, albumin nanoparticles cross-linked with antibodies could connect to its specific ligand on the cell surface to fulfill the active targeting process. ${ }^{32}$ Albumin has also been accepted as a material for the preparation of ultrasound microbubbles because of its innocuity and easy preparation. ${ }^{37}$ In this study, we prepared albumin ultrasound microbubbles and successfully linked them to the constructed albumin nanot-PA plasmid using glutaraldehyde at a final concentration of $0.1 \%(\mathrm{w} / \mathrm{v})$ because microbubbles could be denaturated and destroyed easily at a higher concentration $(1 \%, \mathrm{w} / \mathrm{v})$ of glutaraldehyde and could not be cross-linked with nanoparticles at a lower concentration $(0.05 \%, \mathrm{w} / \mathrm{v})$ of glutaraldehyde. Some researchers found that microbubbles could be reinforced when albumin was mixed with sucrose $(40 \%, \mathrm{w} / \mathrm{v})$ before the microbubbles were prepared. The half-life of the microbubbles was predominantly prolonged from 16 days without sucrose to half a year with it. ${ }^{28}$ In our system, we found that using a $40 \%$ sucrose mixture significantly increased the viscosity of the solution and created difficulty for the ultrasound, which could raise the temperature of the solution dramatically to degenerate albumin. Also, a high concentration of sucrose could not be accepted by the patients when injected into the body. Therefore, $10 \%$ sucrose was chosen for the preparation of the microbubbles with a half-life time of 30 days and very perfect stability. Perfluoropropane is commonly used for the core of microbubbles. Stability of microbubbles in blood and the quality of ultrasound imaging could increase when oxygen is added to the albumin solution before perfluoropropane is given. In this study, oxygen equilibrium before perfluoropropane saturation was used for the preparation of microbubbles. The microbubbles carried with albumin nano-t-PA plasmid could

Table 2 Prothrombin time and INR before and after valve replacement (second, $x \pm s$ )

\begin{tabular}{|c|c|c|c|c|c|c|}
\hline \multirow[t]{2}{*}{ Time (week) } & \multicolumn{2}{|c|}{ Control group } & \multirow[t]{2}{*}{ Cases } & \multicolumn{2}{|c|}{ Experimental group } & \multirow[t]{2}{*}{ Cases } \\
\hline & pro time & INR & & pro time & INR & \\
\hline Before & $7.12 \pm 0.12$ & $0.62 \pm 0.02$ & 8 & $6.56 \pm 0.43$ & $0.59 \pm 0.02$ & 9 \\
\hline \multicolumn{7}{|l|}{ After } \\
\hline 1 & $7.0 \pm 0.78$ & $0.64 \pm 0.06$ & 8 & $6.18 \pm 0.92$ & $0.52 \pm 0.08$ & 9 \\
\hline 2 & $7.53 \pm 0.76$ & $0.62 \pm 0.04$ & 8 & $6.42 \pm 0.98$ & $0.55 \pm 0.96$ & 9 \\
\hline 4 & $7.78 \pm 1.04$ & $0.63 \pm 0.05$ & 6 & $7.97 \pm 1.34$ & $0.60 \pm 0.01$ & 9 \\
\hline 8 & $7.10 \pm 0.00$ & $0.62 \pm 0.02$ & 3 & $6.83 \pm 0.59$ & $0.58 \pm 0.05$ & 9 \\
\hline
\end{tabular}

Note: $P>0.05$ vs all groups.

Abbreviation: INR, international normalized ratio. 
not escape from blood circulation because of its adequate size (2-5 $\mu \mathrm{m}$ in diameter) and easily pass through the pulmonary circulation for heart targeted transfection under the guidance of a therapeutic ultrasound wave. The injective dose of nanotPA gene microbubbles should be considered because of better transfection effectiveness. In a rat experimental study, ${ }^{38} 1 \mathrm{~mL}$ of ultrasound contrast agent (containing $1 \times 10^{9}$ microbubbles with $1 \mathrm{mg}$ plasmid DNA) was needed for heart gene transfection. According to this basal amount, $20 \mathrm{~mL}$ of prepared ultrasound contrast agent (containing $2 \times 10^{10}$ microbubbles linked to nanoparticles with $4 \mathrm{mg}$ plasmid DNA) was given for dog heart transfection, followed by ultrasound imaging reinforcement and recovery after the ultrasound treatment. The transfection effectiveness was measured by a myocardium immunohistochemical stain for t-PA and elevated blood t-PA and D-dimer contents, which reflected the anticoagulative activity, without thrombus found in dog heart cavities after the valve replacement. For unspecific transfection and systemic toxicity, lung, liver, and kidney tissues were also taken for histopathological and immunohistochemical observations. There was little t-PA expression in these tissues with normal morphology, indicating that the transfection was targeting-specific.

Fibrin in thrombus is an inducer for t-PA synthesis. Surgical operation or other injury can induce thrombosis, which is a normal reaction to the injurious stimulation and is followed by elevated blood t-PA and D-dimer contents. ${ }^{39}$ This physiological process will recover after the injury is removed. The persistent elevation of t-PA activity can be obtained after in vivo transfection of its gene. In our previous study, t-PA activity was observed for 3 months after injecting chitosan nano-t-PA plasmid to dog myocardium, which was identified to be feasible to prevent thrombosis after mechanical heart valve replacement. ${ }^{34}$ Increase in production of t-PA in local tissue and in specificity of its function was the major purpose for ultrasound-targeted transfection with diminished systemic influence. In this experimental study, successful transfection followed by elevated blood D-dimer content was obtained without any changes of prothrombin time and INR. It was very important that in this system, t-PA produced only locally activated fibrinolysis and did not influence systemic coagulation, which could prevent bleeding complication from long-term anticoagulative therapy. In addition, the liver is the major organ for t-PA clearance from blood within 10 minutes and also, blood plasminogen activator inhibitor-1 is the important deactivator for it. ${ }^{40}$ This might be why this ultrasound-targeted transfection of t-PA gene could effectively prevent thrombosis after heart valve replacement without any bleeding complications in this study.
Ultrasound-triggered targeted transfection of albumin nano-t-PA gene, in spite of some advantages, is a new technique in primary or experimental situations. Some problems should be settled before applying it clinically. These include: (1) how to construct a safe, effective, and tissue-specific vector and to realize the targeting expression with high effectiveness, stability, and control; (2) how to determine the ratio of nanoparticles and microbubbles with the utmost increase in gene transportation for the best transfection and the ultrasound in density with little ultrasound-triggered tissue injury; (3) how many cells are successfully transfected in one organ or tissue; and (4) the ultrasound contrast agent with the gene may produce micro-embolism in the vessel and the gene or drug may be released to blood, which may be harmful to the body. All of these issues should be thoroughly investigated.

\section{Conclusion}

We successfully fabricated an albumin nano-t-PA gene to an ultrasound-targeted agent that could prevent dog thrombosis after mechanical heart valve replacement. Our study provides an experimental basis for the prevention of human thrombosis-related diseases.

\section{Acknowledgments}

This project was supported by the National 863 plan (No 2007AA021809, No 2007AA021803, No 2007AA021904) and Shenzhen Science and Technology Bureau in China (No 200622). We give special thanks for the technical support from the National Nanolaboratory at ZhongNan University.

\section{Disclosure}

The authors report no conflicts of interest in this work.

\section{References}

1. Haibo Z, Jinzhong L, Yan L, Xu M. Low-intensity international normalized ratio (INR) oral anticoagulant therapy in Chinese patients with mechanical heart valve prostheses. Cell Biochem Biophys. 2012;62(1):147-151.

2. Hammermeister K, Sethi GK, Henderson WG, Grover FL, Oprian C, Rahimtoola $\mathrm{SH}$. Outcomes 15 years after valve replacement with a mechanical versus a bioprosthetic valve: final report of the Veterans Affairs randomized trial. J Am Coll Cardiol. 2000;36(4):1152-1158.

3. Florath I, Albert A, Rosendahl U, Alexander T, Ennker IC, Ennker J. Mid term outcome and quality of life after aortic valve replacement in elderly people: mechanical versus stentless biological valves. Heart. 2005;91(8):1023-1029.

4. Rhie S, Choi JY, Jang IS, Kim JW, Lee CW, Park HO. Relationship between the occurrence of thromboembolism and INR measurement interval in low intensity anticoagulation after aortic mechanical valve replacement. Korean J Thorac Cardiovasc Surg. Jun 2011;44(3): $220-224$. 
5. Kaeberich A, Reindl I, Raaz U, et al. Comparison of unfractionated heparin, low-molecular-weight heparin, low-dose and high-dose rivaroxaban in preventing thrombus formation on mechanical heart valves: results of an in vitro study. J Thromb Thrombolysis. 2011;32(4):417-425.

6. Eikelboom JW, Hirsh J, Spencer FA, Baglin TP, Weitz JI. Antiplatelet Drugs: Antithrombotic Therapy and Prevention of Thrombosis, 9th ed: American College of Chest Physicians Evidence-Based Clinical Practice Guidelines. Chest. 2012;141(Suppl 2):e89S-e119S.

7. Pamukcu B, Huber K, Lip GY. Antiplatelet therapy in atherothrombotic cardiovascular diseases for primary and secondary prevention: a focus on old and new antiplatelet agents. Curr Pharm Des. 2012;18(6):850-860.

8. Lansberg MG, O'Donnell MJ, Khatri P, et al. Antithrombotic and Thrombolytic Therapy for Ischemic Stroke: Antithrombotic Therapy and Prevention of Thrombosis, 9th ed: American College of Chest Physicians Evidence-Based Clinical Practice Guidelines. Chest. 2012; 141(Suppl 2):e601S-e636S.

9. Paez Espinosa EV, Murad JP, Khasawneh FT. Aspirin: pharmacology and clinical applications. Thrombosis. 2012;2012:173124.

10. Wilson AM, Brittenden J, Bachoo P, Ford I, Nixon GF. Randomized controlled trial of aspirin and clopidogrel versus aspirin and placebo on markers of smooth muscle proliferation before and after peripheral angioplasty. J Vasc Surg. 2009;50(4):861-869.

11. Wang MY, Gao CQ, Wang Y, Li BJ, Jiang SL, Ren CL. Analysis on the risk factors of intracardial thrombus after prosthetic valve replacement: a 1-year follow-up study. Zhonghua Wai Ke Za Zhi. 2010;48(7):522-525.

12. Majidzadeh AK, Khalaj V, Fatemeh D, et al. Cloning and expression of functional full-length human tissue plasminogen activator in Pichia pastoris. Appl Biochem Biotechnol. Nov 2010;162(7):2037-2048.

13. Ludwig M, Wohn KD, Schleuning WD, Olek K. Allelic dimorphism in the human tissue-type plasminogen activator (TPA) gene as a result of an Alu insertion/deletion event. Hum Genet. 1992;88(4):388-392.

14. Kim PY, Tieu LD, Stafford AR, Fredenburgh JC, Weitz JI. A high affinity interaction of plasminogen with fibrin is not essential for efficient activation by tissue-type plasminogen activator. J Biol Chem. February 10, 2012; 287(7):4652-4661.

15. Gando S, Sawamura A, Hayakawa M. Trauma, shock, and disseminated intravascular coagulation: lessons from the classical literature. Ann Surg. 2011;254(1):10-19.

16. Kunadian V, Gibson CM. Recombinant tissue-type plasminogen activators: "time matters". Drugs Today (Barc). 2011;47(7):559-570.

17. Chen WH, Lin HS, Chen CI, et al. The medicolegal issue of tissue plasminogen activator in ischemic stroke: a review of judiciary decrees in Taiwan. Acta Neurol Taiwan. 2011;20(3):163-171.

18. Wu ZJ, Yang SF, Zheng SS, Shi D, Wu WW, Li DW. Construction and biological activities of human tPA eukaryotic expression plasmid. Hepatobiliary Pancreat Dis Int. 2004;3(4):511-515.

19. Ekhterae D, Stanley JC. Retroviral vector-mediated transfer and expression of human tissue plasminogen activator gene in human endothelial and vascular smooth muscle cells. J Vasc Surg. 1995;21(6):953-962.

20. Ji S, Ji J, Yang X, Wang X, Ling W, Zhang Y. Experimental study on construction of recombinant t-PA gene plasmid to prevent the thrombosis after mechanical valve replacement. South China J Cardiovas Dis. 2006;12(2):132-135.

21. Ji J, Zhang HW, Zhang ZJ, Ling WP. Transfection of tissue-type plasminogen activator gene to prevent vascular anastomotic restenosis after coronary bypass. China Journal of Modern Medicine. 2007;17(14):1683-1686.

International Journal of Nanomedicine

\section{Publish your work in this journal}

The International Journal of Nanomedicine is an international, peerreviewed journal focusing on the application of nanotechnology in diagnostics, therapeutics, and drug delivery systems throughout the biomedical field. This journal is indexed on PubMed Central, MedLine, CAS, SciSearch $₫$, Current Contents ${ }^{\circledR} /$ Clinical Medicine,
22. Arnedo A, Irache JM, Merodio M, Espuelas Millán MS. Albumin nanoparticles improved the stability, nuclear accumulation and anticytomegaloviral activity of a phosphodiester oligonucleotide. J Control Release. 2004;94(1):217-227.

23. Aynié I, Vauthier C, Chacun H, Fattal E, Couvreur P. Spongelike alginate nanoparticles as a new potential system for the delivery of antisense oligonucleotides. Antisense Nucleic Acid Drug Dev. 1999;9(3):301-312.

24. Wang SB, Yuan F, Wu Y, et al. Nano-carriers for the target treatment of tumor. Journal of Clinical Rehabilitative Tissue Eng Res. 2009;13(29):5739-5742.

25. Wang ZX, Wang ZG. Treatment of ultrasound contrast agents for gene or drug delivery. Chin J Interv Imaging. 2006;3(4):304-308.

26. Casciaro S, Conversano F, Ragusa A, et al. Optimal enhancement configuration of silica nanoparticles for ultrasound imaging and automatic detection at conventional diagnostic frequencies. Invest Radiol. 2010;45(11):715-724

27. Porter TR, Xie F. Therapeutic ultrasound for gene delivery. Echocardiography. 2001;18(4):349-353.

28. Zhao YZ, Lu CT. Recent advances in the applications of ultrasonic microbubbles as gene delivery systems. Yао Хие Хие Вао. 2007;42(2): $127-131$.

29. Lao Y, Xiu JC. Progress of ultrasound microbubble contrast agent with gene and drug targeting therapy. J Med Imaging. 2007;17(12):1359-1361.

30. Zhang YD, Guo Y, Liu WD. Albumin nanoparticles used as gene carrier. Chin J Exp Surg. 2004;21(12):1456-1458.

31. Du YF, Wan MX, Zhao WM. Study on the preparation of a new sugar albumin microbubble ultrasound contrast agent. Yao Xue Xue Bao. 2001;36(11):859-862.

32. Li Xin, He Sheng, GaoYunhua, et al. Study for preparing specific targeted ultrasound contrast agent. Chinese J Ultrasound Med. 2007;23(7):493-495.

33. Ling ZY, Wang Z, Ran HT, et al. Experiment study on ultrasoundmediated microbubble destruction deliver VEGF gene to ischemic myocardium of rats. Chinese Ultrasound Med. 2002;18(7):502-504.

34. Ji S, Jun J, Xiaohan Y, et al. Study on construction of nano tPA plasmid to prevent thrombosis after mechanical valve replacement in dogs. J Surg Res. 2011;168(1):e1-e5.

35. Arnedo A, Espuelas S, Irache JM. Albumin nanoparticles as carriers for a phosphodiester oligonucleotide. Int J Pharm. 2002;244(1-2):59-72.

36. Wang K, Ma GH. Preparation and characterization of albumin nanospheres as drug carrier. Chinese J Pro Eng. 2004;4(2):156-159.

37. Liu XB, Cai MY. Preparation and immunological characterization of mitoxantrone-loaded immuno-nanoparticles against human hepatoma. Chinese J Immuno. 2000;16(5):2622265-2622269.

38. Ferrara K, Pollard R, Borden M. Ultrasound microbubble contrast agents: fundamentals and application to gene and drug delivery. Annu Rev Biomed Eng. 2007;9:415-447.

39. Chopra N, Doddamreddy P, Grewal H, Kumar PC. An elevated D-dimer value: a burden on our patients and hospitals. Int J Gen Med. 2012;5:87-92. Epub January 25, 2012.

40. Urano T, Suzuki Y. Parameters related to fibrinolysis and their meanings. Rinsho Byori. 2011;59(7):703-708.

Journal Citation Reports/Science Edition, EMBase, Scopus and the Elsevier Bibliographic databases. The manuscript management system is completely online and includes a very quick and fair peer-review system, which is all easy to use. Visit http://www.dovepress.com/ testimonials.php to read real quotes from published authors. 